\title{
Improving mass balance of municipal solid waste through waste reduction by informal sectors
}

\author{
Christia Meidiana $^{{ }^{*}}$, Sekito Tomoo $^{2}$, Devi Agustina ${ }^{1}$, and Aris Subagiyo ${ }^{1}$ \\ ${ }^{1}$ Department of Regional and Urban Planning, University of Brawijaya, Malang, Indonesia \\ ${ }^{2}$ Department of Civil and Environmental Engineering, University of Miyazaki, Miyazaki, Japan
}

\begin{abstract}
A study on the mass flow of municipal solid waste in a mediumsize-city was conducted to analyze the potential waste reduction through the informal sector. The city was opted since the local government targets to improve the informal sector's role to reduce the waste, which is relatively reasonable to implement the informal sector involvement rather than high technology in waste management requiring high investment, which can be challenging for the local government. Waste Bank and scavengers are informal sectors mainly involved in waste reduction in the area of study. Their capacity to reduce domestic waste was evaluated using a mass balance method. The recovery factor of each waste type was also calculated to determine the average reduction rate. The result showed that scavengers and cleaning staff working in temporary waste disposal sites (TWDSs) could reduce the waste collected daily up to $70 \%, 61 \%, 48 \%, 50 \%, 3 \%$ for paper, plastic, glass, metal, and organic waste respectively. Calculation using mass balance showed that 17 TWDS reduce a total of $8 \%$ waste per year, while 13 waste banks reduce $2 \%$ waste per year. It indicated that waste reduction in the city was only $10 \%$. The reduction rate is far below the target of the government, which is $20 \%$ by 2020 . Therefore, the study proposes improving the mass balance by increasing the waste treatment capacity in TWDSs and waste banks. By adding the shredder and composting heaps in some TWDSs and the number of active members in waste banks, the waste reduction may increases from $10 \%$ to $24 \%$.
\end{abstract}

\section{Introduction}

According to a recent study, the annual solid waste collection is about 11.2 billion globally, which decomposition of its organic fraction contributes about 5 percent of global greenhouse gas emissions [1]. There is no appropriate intermediate treatment for municipal waste in Indonesia before disposal in the landfill. Most landfills in Indonesia are already over capacity and need intensive treatment [2]. According to Damanhuri (2017), approximately 69\% of waste is disposed of in a landfill, and $10 \%$ of waste is disposed of with no treatment [3]. Although Waste Law. 18/ 2018 requires all landfills and dumpsites to be transformed into

\footnotetext{
* Corresponding author: c_meideiana@ub.ac.id
} 
either sanitary landfills or controlled landfills. Only a few cities comply with the law. This condition has led to a vast environment and social problem [2].

Dumping of municipal solid waste (MSW), either environmentally-friendly (sanitary or controlled landfill) or detrimental (open dumpsite), may be harmful to environments such as water, soil, and air pollution [4]. The open dumpsite is highly risky and commonly applied in the developing world $[5,6,7]$. The open dumpsite is often chosen as a solution to municipal waste management for lacking technical and financial reason disturbs the natural ecosystem and interferes sustainability of the local environment [8]. It also emits harmful gasses and leachate, both surrounding affecting areas [4]. Therefore, the GoI promotes sustainable waste management by introducing some regulations changings the old paradigm of waste management, which was the end-pipe-solution comprising of waste collectiontransportation-disposal shifted to the new one, waste minimization by reduction before final disposal.

Waste disposal is an essential component of waste management. Fast population growth, high urbanization rate, and growing economic development cause an escalation of waste generation [9], and it becomes a significant challenge in many developing countries worldwide [10]. In these countries, waste management issues often represent major environmental problems due to limited municipal budgets, lacking understanding, and weak data availability [11].

Waste reduction is an example of the new paradigm of waste management besides waste reuse and recycling. It is currently promoted and legally supported by the GoI through Government Regulation No. 81/2012, defining the importance of waste reduction of domestic waste through reduction, reuse, and recycling (3R). The regulation is essential since the GoI targets to achieve a $20 \%$ waste reduction by 2019 . This target is updated to be a $30 \%$ waste reduction by 2030 . The $3 \mathrm{R}$ can be conducted through some methods which are mainly implemented on a community scale. Therefore, local communities play an essential role in waste reduction typically conducted in small-scale waste recycling systems $[12,13]$. The community usually represented by the households, ) do mostly only waste reduction and reuse in the initial stage before the waste collection. In the further stages, the activities of $3 \mathrm{R}$ involve informal groups, i.e., scavengers and garbage truck helpers or cleaning staff $[14,15$, $16,17,18]$. One of the strategies initiated by the Ministry of Environment (MoE) to promote waste reduction is by implementing a waste bank model. Therefore, the MoE issued the Regulation of the Minister of Environment 13/2012 on 3R through a waste bank (WB).

WB is implementing the $3 \mathrm{R}$ concept in waste management involving the community [19, $20,21]$ and is commonly implemented in some Southeast Asian countries [22]. There are some benefits to waste bank. According to [23], it promotes public awareness to separate and reduce waste, while [24] described WB supports the creation of a clean and healthy environment and contributes side income to the society [23, 24]. WB at the grassroots level can increase the income of urban poor people [25]. WB is essentially social engineering to engage people in managing waste by buying back waste in a deposit like the banking system [24]. Since it works similar to the banking system, membership is a prerequisite, and it can be an individual or a group. The members can exchange recyclable materials for revenue according to the waste weight of each waste type [26]. Revenue is then deposited into personal accounts, from which members can withdraw cash in a certain period.

The development of WB in Indonesia is promising. The number of waste banks is continuously increasing since the first WB has been founded in Yogyakarta (2008), followed by Malang and Surabaya in 2010. The Ministry of Environment identified an increase of 1,221 waste banks in just four years from 2011 to 2015 [27]. Meanwhile, data from Statistics Indonesia showed that in 2014 there were 1,172 WBS. This number became 7,488 in 2018, indicating a fivefold increase. This number is expected to grow and sustainable to achieve the national waste reduction target in 2030 . However, preliminary study in some cities and 
Indonesia, i.e., Mojokerto, Probolinggo, and Semarang, showed that many WBs built and registered is inactive or even shut down.

The other informal sector involving in waste reduction is a scavenger. Scavenging or waste-picking commonly occurs in developing countries, including Indonesia, since it provides benefits such as income sources for scavengers and waste reduction for local government. This informal sector currently provides two out of three jobs worldwide [28]. According to [29], Scavengers play an important role in solid waste management because their activity contributes to waste reduction, minimization, and material recovery. Recyclable material sorted contains significant values making scavenging a profitable business for lowincome people may attract more people to be involved in such a business. It contributes to the income increase for poor people in developing countries [30]. In Indonesia, the scavengers can reduce waste significantly that most local governments permit them to pick the waste from source (domestics/public) to endpoint (landfill). For instance, scavenging accounts for $40 \%$ of the waste recycled in Yogyakarta [31]. Even higher rates are attained in Surabaya, where waste-pickers handle one-third of all city waste and recycle around $50 \%$ of the waste collected.

The improvement of WB's performance and the scavenger's capacity to separate the waste can support the local government to achieve the 30\%-waste reduction-target. However, no recent studies focus on waste reduction by informal sectors at the city level, especially in Mojokerto. There are 17 TWDS and 13 WBS having the potentials to reduce the waste. However, the current masterplan of waste management shows that the reduction rate below $10 \%$. Therefore, the study aims to evaluate its capacity to reduce domestic waste and improve waste reduction capacity.

\section{Method}

Quantitative research technique is used in this research enabling calculation of the amount of waste reduced by informal sectors in waste banks and temporary waste disposal sites (TWDSs). The results of the calculation are used as variables in scenario development to increase waste reduction. Data is collected through a survey conducted in 16 TWDS and 13 waste banks where waste sorting and separation and reduction occur for seven days in Mojokerto City. The analysis is conducted within the system boundary set beforehand. The system boundary in this study is described in Figure 1.

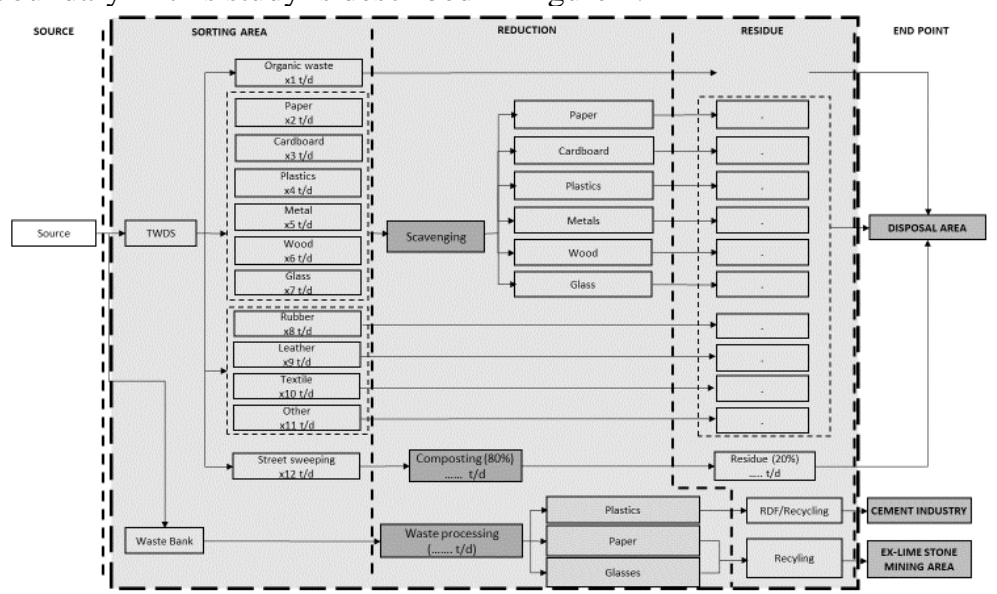

Fig. 1. The system boundary of the study (Author's Analysis, 2020) 


\subsection{Mass balance analysis}

Waste flow within the boundary is identified using mass balance analysis (MBA). In MBA, calculation of material flow to and out from the system is carried out. Using MBA, a fraction of material can be used as input for other processes called recovery factor is calculated, enabling the estimation of material recovery in the future. Figure 2 describes the principles of an MBA.

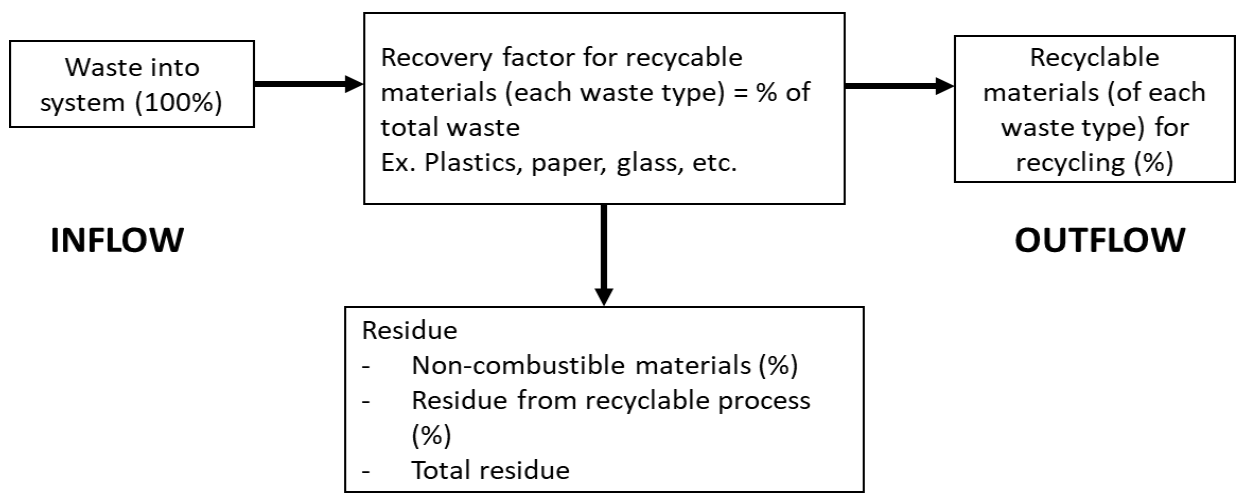

Fig 2. An Example of Mass Balance Analysis for Refused Derived Fuel Production (Author's Analysis, 2020)

\section{Results and discussion}

\subsection{Waste flow}

Mojokerto City population of 136.363 with average waste generation is $0.4 \mathrm{~kg} / \mathrm{cap} /$ day producing $54,549.2 \mathrm{~kg}$ waste/day or about 19,910,458 $\mathrm{kg} /$ year. However, the Level of Service of waste collection is $92.1 \%$, indicating that some waste is managed by the community properly or improperly. Most waste in Mojokerto City is collected and transported to 17 TWDSs and one transfer point (Fig 3). In TWDS, recyclable waste is sorted and separated from mixed waste by scavengers, while in the transfer point, all waste is recyclable waste that the reduction rate is $100 \%$. A small fraction of recyclable waste is separated by the households to be sold to the 13 waste banks in Mojokerto City. This activity benefits both community and local government since there is side income for households by selling the recyclable material. Moreover, it helps the local government reduce waste source points contributing less waste transported to TWDS and landfills.

\subsection{Recovery factor}

The average recovery factor for all TWDSs in Mojokerto City based on the waste type is $70 \%, 61 \%, 48 \%, 50 \%, 3 \%$ for paper, plastic, glasses, metal, and organic waste, respectively. Organic waste has the lowest recovery factor because only one TWDS which separates and treats the organic waste.

\subsection{Waste reduction}

Waste reduction occurs in TWDSs and WBs. Figure 3 shows that 13 WBs reduces 447.426 $\mathrm{kg}$ of recyclable waste per year, which equals $2 \%$ of the total waste generation. Meanwhile, 
$18.336 .638 \mathrm{~kg}$ of waste is collected and transported to 16 TWDS and one transfer point per year. Waste reduction in TDWSs is conducted by scavengers and cleaning staff amounted to $434,968 \mathrm{~kg} /$ year and $918.780 \mathrm{~kg} /$ year for recyclable waste and organic waste. This amount equals to $2 \%$ and $5 \%$ for each waste type, respectively. Waste reduction through waste banks and scavenging in TWDS reduce the total amount of waste transported to the landfill, which is $18,051,156 \mathrm{~kg} /$ year indicating that $91 \%$ of waste generated in Mojokerto is treated in the landfill, and the waste reduction is only $9 \%$. This percentage is far below the national target, which is a $20 \%$ waste reduction in 2019. Therefore, the local government should increase the reduction capacity both through waste separation in TWDS and WB. Figure 3 describes the stable waste management system in Mojokerto City. Starting from the source of waste, collection stage to the endpoint at the TPA. Each stage is analyzed to measure each stage's performance to get an overview of the condition of solid waste management in Mojokerto City.

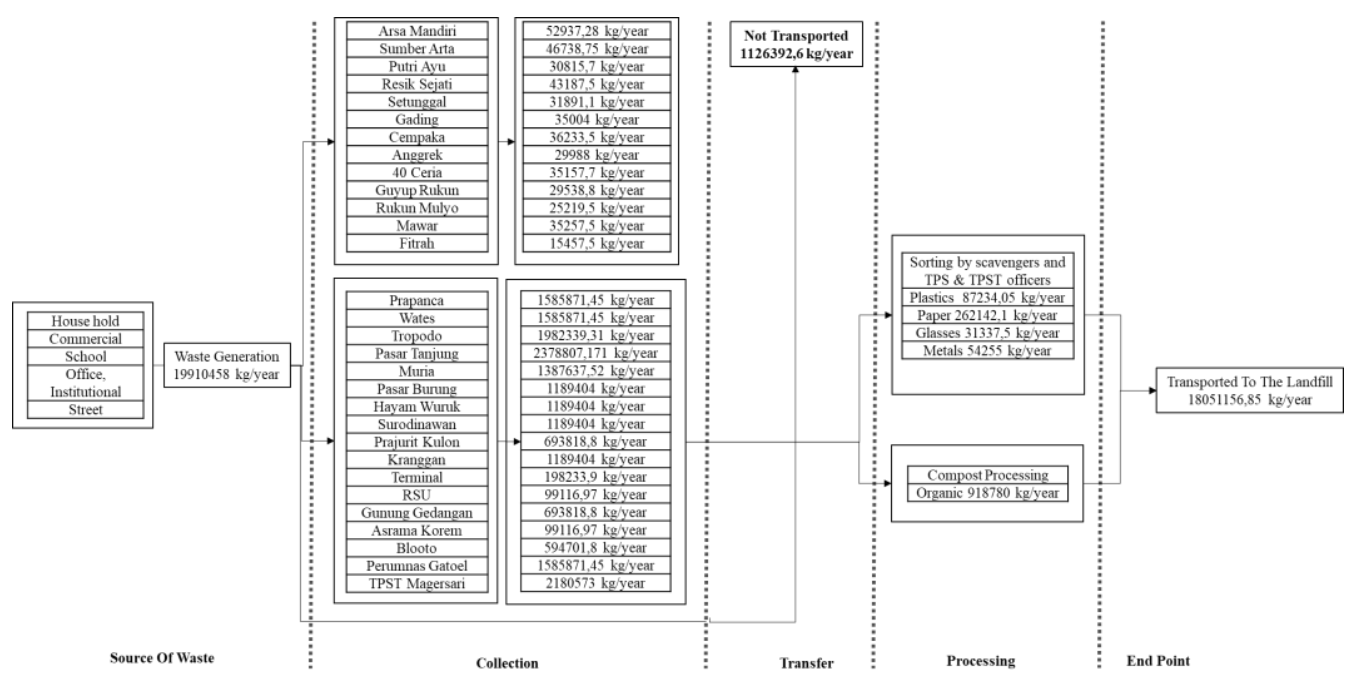

Fig 3. Waste Flow from source (generator) to endpoint (landfill) in Mojokerto City (Author's Analysis)

\subsection{Potentials waste reduction through WBs and TWDSs enhancement}

Some improvements are proposed in this study. The recovery factor in TWDSs is increased by adding some equipment to optimize waste separation and treatment. Waste reduction capacity in WBs increased by encouraging the old members to sell more waste and adding new members. This study also proposes nine new WBs to be founded, which may increase the reduction rate to $4 \%$. The calculation of these improvements demonstrates that TWDS and transfer point may contribute $567,777 \mathrm{~kg}$ and $3,195,888 \mathrm{~kg}$ recyclable waste and organic waste reduction per year, respectively. It equals to $3 \%$ and $16 \%$ reduction of recyclable waste and organic waste, respectively. It can be concluded that the improvements mentioned above can increase the waste reduction to $23 \%$, which can reduce waste transportation to the landfill by about 2,500 tons/year. Referring to the result of the calculation, the formal and informal sector's involvement in waste management can increase waste reduction. However, the formal sector represented by the Cleaning Department of the local government should be the central pillar to achieve the waste reduction target. The department should also increase the waste collection up to $100 \%$ through the informal waste sector's contribution, represented by scavenger and waste bank playing a supporting role rather than the primary role. Local 
government should support the existing WBs to improve their performance through capacity building or equipment provision.

\section{Conclusion}

Improving Mass Balance of Municipal Solid Waste is analysed in this study to increase waste reduction through informal sectors. The results of the analysis show that waste separation and treatment in 16 TWDS and one transfer point contributes $7 \%$ waste reduction. Meanwhile, waste separation in 13 waste banks reduces recyclable waste up to $2 \%$. However, the recovery factor for each waste type is relatively low. Therefore, it is necessary to encourage the the old members to sell more waste. Two more conditions which are adding new members and forming nine new waste banks are proposed. These three activities may contribute $4 \%$ waste reduction. Furthermore, by providing adequate equipment in TWDS to separate and treat the waste can increase waste reduction up to $3 \%$ and $16 \%$ of total waste for recyclable waste and organic waste, respectively. Totally, $23 \%$ waste reduction can be achieved through improvement of mass balance of MSW reducing waste transportation to the landfill by about 2,500 tons/year consequently.

\section{References}

1. UNEP, Solid waste management (2020)

2. B. Lokahita, G. Samudro, H. S. Huboyo, M. Aziz, and F. Takahashi, Energy Procedia, 158 (2019)

3. E. Damanhuri, State 3Rs Asia Pacific, pp. 1-55 (2017)

4. K. Mahmood, Z. Ul-haq, F. Faizi, S. Tariq, M. Azhar, and A. Daud, Ecol. Indic, 107 (2019)

5. K. Mahmood, A. Batool, F. Faizi, M.N Chaudhry, Z. Ul-haq, A.D, Rana, S. Tariq, Ecol. Indic, 82 (2017)

6. K. Mahmood, A. Batool, M.N Chaudhry, Waste Manage, 55 (2016)

7. K. Mahmood, Z. Ul-haq, A. Batool, F. Faizi, Waste Manage. Res., 37 (2018)

8. R. A. Bellezoni, C. K. Iwai, V. R. Elis, W. da Silva Paganini, and J. Hamada, Environ. Earth Sci., 71 (2014)

9. K. Laohalidanond, P. Chaiyawong, and S. Kerdsuwan, Energy Procedia, 79 (2015)

10. A. Soni, D. Patil, K. Argade, Procedia Environ. Sci., 35 (2016)

11. H. I. Abdel-Shafy and M. S. M. Mansour, Egypt. J. Pet., 27 (2018)

12. T. Sekito, T. B. Prayogo, C. Meidiana, H. Shimamoto, and Y. Dote, Environ. Dev. Sustain., 21 (2019)

13. H. D. Purba, C. Meidiana, and D. W. Adrianto, Int. J. Environ. Sci. Dev., 5 (2014)

14. F. Fei, L. Qu, Z. Wen, Y. Xue, and H. Zhang, Resour. Conserv. Recycl., 110 (2016)

15. C. Ezeah, J.A. Fazakerley, C.L, Roberts, Waste Manage., 33 (2013)

16. S. Sasaki, T. Araki, A. H. Tambunan, and H. Prasadja, Resour. Conserv. Recycl., 89 (2014)

17. M. Asim, S. A. Batool, and M. N. Chaudhry, Resour. Conserv. Recycl., 58 (2012)

18. C. Meidiana, H.A. Yakin, W.P. Wijayanti, Intech Open (2017)

19. S. Suttibak, V. Nitivattananon, Resour. Conserv. Recycl., 53 (2008)

20. S. Aroonsrimorakot and P. Pradabphetrat, J. Environ. Res., 32 (2010)

21. W. Singhirunnusorn, K. Donlakorn, and W. Kaewhanin, Procedia - Soc. Behav. Sci., 36 (2012)

22. D. R. Wijayanti and S. Suryani, Procedia - Soc. Behav. Sci., 184 (2015)

23. D. Asteria and H. Heruman, J. Mns. dan Lingkung., 23 (2016) 
24. A. Pariatamby, M. Tanaka, Municipal Solid Waste Management in Asia and the Pasific Island: Challenges and Strategic Solutions (2014)

25. H. Winarso and A. Larasati, J. Mns. dan Lingkung., 18 (2011)

26. E. Friedberg, M.E. Hilderbrand, Observing Policy-Making in Indonesia (2017)

27. Ministry of Environment and Forestry. http://ppid.menlhk.go.id/siaran_pers/browse/1667. December 2018

28. P. Navarrete-Hernandez and N. Navarrete-Hernandez, World Dev., 101 (2018)

29. M. Aljaradin, K. M. Persson, and E. Sood, Resources and Env., 5 (2015)

30. C. Series, J. Phys. Conf. Ser., 1469 (2020)

31. M. Medina, Scrap and trade: Scavenging myths. New York: United Nations University (2010) 